\title{
Minireview Epidemiology of soy exposures and breast cancer risk
}

\author{
AH Wu', $\mathbf{u}^{*, 1} \mathrm{Yu}^{2}, \mathrm{C}-\mathrm{C}$ Tseng' and MC Pike'

 \\ Minnesota, Minneapolis, MN, USA
}

\begin{abstract}
Most of the early studies published on soy and breast cancer were not designed to test the effect of soy; the assessment of soy intake was usually crude and few potential confounders were considered in the analysis. In this review, we focused on studies with relatively complete assessment of dietary soy exposure in the targeted populations and appropriate consideration for potential confounders in the statistical analysis of study data. Meta-analysis of the 8 (I cohort, 7 case-control) studies conducted in high-soy-consuming Asians show a significant trend of decreasing risk with increasing soy food intake. Compared to the lowest level of soy food intake $(\leqslant 5 \mathrm{mg}$ isoflavones per day), risk was intermediate $(O R=0.88,95 \%$ confidence interval $(C l)=0.78-0.98)$ among those with modest ( 10 mg isoflavones per day) intake and lowest $(\mathrm{OR}=0.7 \mathrm{I}, 95 \% \mathrm{Cl}=0.60-0.85)$ among those with high intake ( $\geqslant 20 \mathrm{mg}$ isoflavones per day). In contrast, soy intake was unrelated to breast cancer risk in studies conducted in the 1 I low-soy-consuming Western populations whose average highest and lowest soy isoflavone intake levels were around 0.8 and $0.15 \mathrm{mg}$ per day, respectively. Thus, the evidence to date, based largely on case-control studies, suggest that soy food intake in the amount consumed in Asian populations may have protective effects against breast cancer.
\end{abstract}

British Journal of Cancer (2008) 98, 9- |4. doi: I0.1038/sj.bjc.6604I45 www.bjcancer.com

Published online 8 January 2008

(C) 2008 Cancer Research UK

Keywords: soy; Asian and Western populations; breast cancer

Soybeans and its products have been a staple in the Asian diet for centuries. Soybeans are the predominant source of isoflavones, one of the three main classes of phytoestrogens or plant oestrogens. Genistein and daidzein are the two major isoflavones; glycitein is a minor component. These soy isoflavone compounds are structurally similar to $17-\beta$ estradiol but possess weaker oestrogenic potencies. Given the recognised aetiologic association between oestrogen and breast cancer risk, there is biological plausibility that dietary soy intake may have anti-carcinogenic effect on the breast. A favoured mechanism by which soy isoflavones may influence breast cancer development is via their affinity and competition with endogenous oestrogens and other substrates in binding with oestrogen receptors (ERs). It has also been suggested that soy isoflavones may influence breast cancer risk via their antiproliferative, anti-angiogenic, anti-oxidative and anti-inflammatory properties (Gilani and Anderson, 2002).

Lee et al (1991) first reported a reduced risk of breast cancer in premenopausal Singapore Chinese women who were high consumers of soy. Since then, there has been tremendous interest in the possible role of soy in the prevention of breast cancer. However, there is also the concern that soy may have stimulatory effects on the breast. Dietary genistein and highly processed soy

\footnotetext{
* Correspondence: Dr AH Wu, Department of Preventive Medicine, Keck School of Medicine, University of Southern California, I44I Eastlake Avenue, MC 9175, Los Angeles, CA 90089-9175, USA;

E-mail: annawu@usc.edu

Received II September 2007; revised 9 November 2007; accepted 19 November 2007; published online 8 January 2008
}

agents have been found to stimulate growth in the MCF-7 breast cancer cells, and to promote breast cancer in ovaraectomised athymic mice models (for a review, see Messina et al, 2006). In a short term soy-feeding trial, women randomised to the soy arm exhibited significantly higher indices of increased DNA synthesis relative to women in the control arm, although this apparent association failed to persist following the inclusion of 33 additional subjects (Hargreaves et al, 1999).

The questions we would like to address in this review are as follows: (1) What is the epidemiologic evidence on soy and breast cancer? Is there a dose-response relationship? (2) Does the endogenous oestrogen environment, as reflected by menopausal status and body weight, affect this association? (3) Does timing of soy exposure affect this association? (4) Does the type of soy ingested affect this association, given that it can be consumed in the form of soy products that are common in a typical Asian diet or as fillers/extenders in processed foods?

We identified a total of 28 epidemiologic studies in English language with sufficiently detailed information on soy and breast cancer risk. Fourteen studies were included in the meta-analysis by Trock et al (2006). Of the remaining 14 studies, 6 were conducted in Asia (Hirose et al, 2005; Lee et al, 2005; Shannon et al, 2005; Ho et al, 2006; Do et al, 2007; Nishio et al, 2007) while the rest were conducted in various Western populations (Peterson et al, 2003; dos Santos Silva et al, 2004; Keinan-Boker et al, 2004; Bosetti et al, 2005; Thanos et al, 2006; Touillaud et al, 2006; Fink et al, 2007; Verheus et al, 2007). Given that Asians differ from Western populations in terms of types and amounts of soy consumed, and possess distinct characteristics linked to breast cancer risk, we 
conducted separate meta-analysis on epidemiologic data derived from Asians and Western populations, respectively.

\section{RISK ASSOCIATION STUDIES IN HIGH-SOY-CONSUMING ASIANS}

In Asia, soy food is consumed traditionally as nonfermented soy foods (tofu, sometimes known as bean curd, soybeans and soy milk), fermented soy foods (miso and natto) or other soy products (fried, dried and pressed soy products), and the average intake is between 25 and $50 \mathrm{mg}$ of isoflavones per day (Messina et al, 2006). In contrast, intake of soy isoflavones in Western populations is usually less than $1.0 \mathrm{mg}$ of isoflavones per day and Asian soy foods are rarely consumed. Their sources of soy isoflavones come from some legumes, sprouts and vegetables containing small amounts of isoflavones, and from soy flour and soy protein that are commonly added as extenders and fillers in different bakery and canned goods (Horn-Ross et al, 2001).

Eight of the 14 studies conducted in Asia or in Asian Americans captured the main sources of soy intake and carefully adjusted for relevant dietary and non-dietary potential confounders. We excluded the remaining six (two cohort, four case-control) studies from the meta-analysis due to incomplete assessment of soy intake in those studies. Specifically, two studies (Wu et al, 1996; Ho et al, 2006) examined only about intake of tofu. Four other studies (Yuan et al, 1995; Key et al, 1999; Hirose et al, 2003; Nishio et al, 2007) asked about intake of several soy foods that captured between 40 and $60 \%$ of total soy intake in those populations.

In the eight (one cohort, seven case-control) studies with relatively complete assessment of total soy intake, dietary soy exposure was expressed in varying units, including grams of soy foods per day (Lee et al, 1991, 2005; Hirose et al, 2005; Shannon et al, 2005; Do et al, 2007), grams of soy protein per day (Lee et al, 1991; Dai et al, 2001), and milligrams of soy isoflavones per day (Wu et al, 2002; Yamamoto et al, 2003; Hirose et al, 2005). To facilitate comparison between individual studies, all dietary soy exposures were converted to units of milligram of isoflavones assuming that $1 \mathrm{~g}$ of soy protein or $10 \mathrm{~g}$ of soy food contain $3 \mathrm{mg}$ of isoflavones (Messina et al, 2006; Trock et al, 2006).

Table 1 shows the meta-analysis of these eight studies with information on total soy food intake and breast cancer in Asian women. There was a statistically significant $29 \%$ reduction in the risk of breast cancer associated with high soy intake (summary $\mathrm{OR}=0.71,95 \%$ confidence interval $(\mathrm{CI})=0.60-0.85$ ) compared to the lowest level of soy intake (Table 1). Results of the individual studies are shown in Figure 1A. Across these Asian studies, the median cut point of the highest intake of soy isoflavones was $20 \mathrm{mg}$ or more per day and the lowest intake was $5 \mathrm{mg}$ or less per day. A moderate level of soy intake (median was approximately $10 \mathrm{mg}$ isoflavones per day) was associated with a statistically significant $12 \%$ reduction in risk (summary $\mathrm{OR}=0.88,95 \% \mathrm{CI}=0.78-0.98)$ compared to the lowest level of soy intake (Figure 1B). All but one of the studies was conducted in Asia; exclusion of the study conducted among Asian Americans (Wu et al, 2002) did not materially change the overall summary risk estimate. Only one of these studies was a cohort study (Yamamoto et al, 2003); the summary OR of the seven casecontrol studies combined was similar to overall results. Test of heterogeneity across these eight studies comparing highest $v s$ lowest level of soy intake showed statistically significant heterogeneity $(P=0.023)$ that was due largely to the findings of one hospital-based case-control study, which found an increased risk associated with high soy intake (Lee et al, 2005) (Figure 1A). The results across the remaining seven studies were comparable; the summary $\quad \mathrm{OR}$ was $0.66 \quad(95 \% \quad \mathrm{CI}=0.55-0.78) \quad(P$ heterogeneity $=0.32$ ) comparing the highest to the lowest level of soy intake. There was no significant heterogeneity across these
Table I Soy intake and breast cancer risk - eight studies conducted in Asia and in Asian Americans

\begin{tabular}{|c|c|c|c|}
\hline Description & $\begin{array}{l}\text { No. of } \\
\text { studies }\end{array}$ & Odds ratio & $\begin{array}{l}95 \% \text { confidence } \\
\text { interval }\end{array}$ \\
\hline \multicolumn{4}{|c|}{ Highest ( $20 \mathrm{mg}$ or more isoflavone per day) vs lowest ( $\sim 5 \mathrm{mg}$ or less isoflavone per day) } \\
\hline All studies ${ }^{\mathrm{a}}$ & 8 & 0.71 & $(0.60-0.85)$ \\
\hline $\begin{array}{l}\text { All studies in } \\
\text { Asia }^{\mathrm{b}}\end{array}$ & 7 & 0.73 & $(0.61-0.89)$ \\
\hline $\begin{array}{l}\text { Case-control } \\
\text { studies }^{c}\end{array}$ & 7 & 0.75 & $(0.62-0.89)$ \\
\hline $\begin{array}{l}\text { Premenopausal } \\
\text { women }\end{array}$ & 6 & 0.65 & $(0.50-0.85)$ \\
\hline $\begin{array}{l}\text { Postmenopausal } \\
\text { women }^{\text {d }}\end{array}$ & 6 & 0.63 & $(0.46-0.85)$ \\
\hline
\end{tabular}

Moderate ( $\sim 10 \mathrm{mg}$ isoflavone per day) vs lowest ( $\sim 5 \mathrm{mg}$ isoflavone or less per day) All studies $^{\mathrm{e}} \quad 8 \quad 0.88 \quad(0.78-0.98)$

aStudies included in meta-analysis: Lee et al (1991); Dai et al (200I); Wu et al (2002); Yamamoto et al (2003); Hirose et al (2005); Lee et al (2005); Shannon et al (2005); Do et al (2007). We calculated ORs associated with soy products (in g) for pre- and postmenopausal women combined in the study by Lee et al (199|); the results in postmenopausal women in this study were published in a 1992 paper. We also calculated ORs for pre- and postmenopausal women combined in Hirose et a

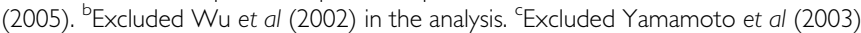
in the analysis. ${ }^{d}$ Results were not presented by menopausal status in two studies (Dai et al, 200 I; Shannon et al 2005) and they were excluded in this analysis. Do et al (2007) published the data in pre- and postmenopausal women separately in a subsequent paper in 2007. 'Results were presented by tertiles (Lee et al, 1991: Hirose et al, 2005), quartiles (Wu et al, 2002; Yamamoto et al, 2003; Lee et al, 2005 Shannon et al, 2005; Do et al, 2007) and deciles (Dai et al, 200I) of soy intake. Risk estimate for moderate intake was calculated using the ORs for deciles 5 and 6 in Dai et al (200I) and the ORs for quartiles 2 and 3 in studies which presented results by quartiles of soy intake.

eight studies comparing moderate $v s$ lowest level of soy intake $(P$ heterogeneity $=0.60)($ Figure $1 \mathrm{~B})$.

Results were presented by menopausal status in six of these studies; a significant inverse association was observed in both pre-menopausal (summary $\mathrm{OR}=0.65,95 \% \mathrm{CI}=0.50-0.85$ ) and postmenopausal women (summary $\mathrm{OR}=0.63,95 \% \mathrm{CI}=0.46$ 0.85) (Table 1). Few studies have investigated whether body size modify the soy-breast cancer association, particularly in postmenopausal women. Investigators in Shanghai, China, reported that the inverse soy-breast association was more evident in women with higher body mass index (BMI) $\left(\geqslant 25 \mathrm{~kg} \mathrm{~m}^{-2}\right)$ than their lower BMI counterparts (Dai et al, 2001). The authors did not perform separate analyses in the pre- $v s$ postmenopausal women whose endogenous oestrogen environments were vastly different. Premenopausal women represented about $65 \%$ of the subjects in this Shanghai study. In our Los Angeles Asian Breast Cancer study, we did not observe any clear modifying effects of BMI on the soybreast cancer association in either pre- or postmenopausal women (unpublished data).

Two studies asked about intake of soy during adolescence. In Shanghai, soy intake during adolescence is associated with a greater risk reduction than adult intake (Shu et al, 2001). Similarly, in the Los Angeles Asian Breast Cancer Study, we found that soy intake during adolescence exhibited a stronger protective effect on risk than adulthood exposure (Wu et al, 2002). Compared to women who were low soy consumers during both adolescence and adult life, women who were low soy consumers during adolescence but were high-soy consumers during adult life displayed modestly reduced risk without reaching statistical significance $(0.88,95 \%$ $\mathrm{CI}=0.61-1.18)(\mathrm{Wu}$ et al, 2007a)

We also examined the results of the six excluded studies (due to incomplete soy assessment) (Yuan et al, 1995; Wu et al, 1996; Key 
A

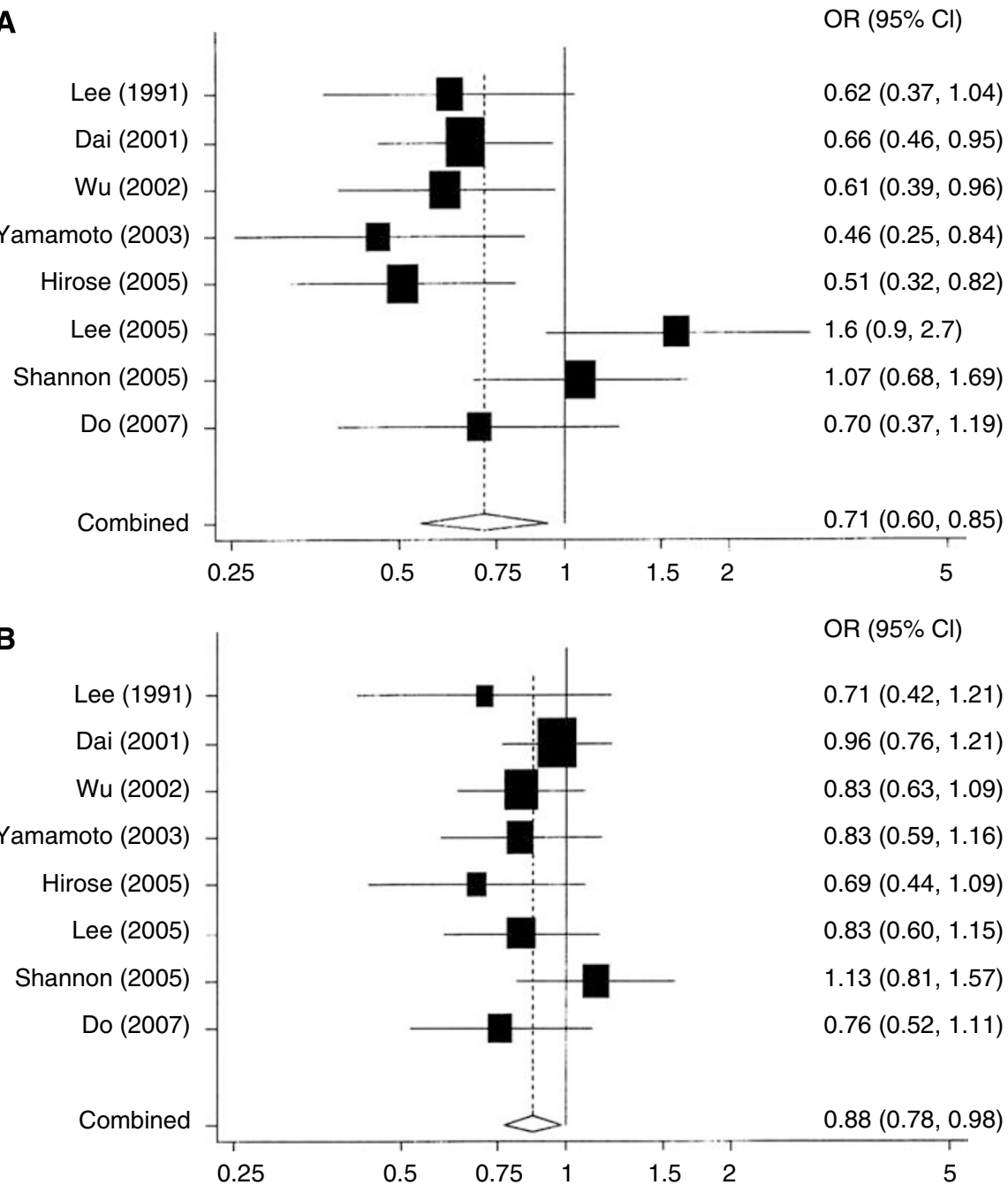

Figure I (A) Highest ( $\sim 20 \mathrm{mg}$ or more isoflavones per day) vs lowest ( $\sim 5 \mathrm{mg}$ or less isoflavone per day) level of soy intake and breast cancer - eight studies conducted in Asia and in Asian Americans. (B) Moderate ( $\sim 10 \mathrm{mg}$ isoflavones per day) vs lowest ( $\sim 5 \mathrm{mg}$ or less isoflavone per day) level of soy intake and breast cancer - eight studies conducted in Asia and in Asian Americans. See footnote e of Table I.

et al, 1999; Hirose et al, 2003; Ho et al, 2006; Nishio et al, 2007) with findings of our meta analysis based on the remaining eight studies in Asians (Table 1). A comparison of the reported ORs and their $95 \%$ CIs in the excluded studies with the summary OR $(95 \%$ CI) showed the results of the excluded studies to be mostly compatible with the findings of the meta-analysis.

\section{RISK ASSOCIATION STUDIES IN LOW-SOY- CONSUMING WESTERN POPULATIONS}

In studies conducted in Western populations (including one study of South Asians in the United Kingdom, daily soy isoflavone intake was estimated based on intake of certain traditional Asian soy foods and other food items for which values of isoflavones are available and have been compiled into various databases. Average intake of soy isoflavones was low (median was approximately $0.3 \mathrm{mg} \mathrm{day}^{-1}$ ) in these Western populations. Traditional Asian soy foods contributed little to the total intake of soy isoflavones in these studies: it was 3\% in Norfolk-United Kingdom (Grace et al, 2004), 7\% in Ultrecht, the Netherlands (Keinan-Boker et al, 2004), $24 \%$ in Germany (Linseisen et al, 2004) and $35 \%$ in the San
Table 2 Soy intake and breast cancer risk - II studies conducted in Western populations

\begin{tabular}{|c|c|c|c|}
\hline Description & $\begin{array}{l}\text { No. of } \\
\text { studies }\end{array}$ & Odds ratio & $\begin{array}{l}95 \% \text { confidence } \\
\text { interval }\end{array}$ \\
\hline \multicolumn{4}{|c|}{$\begin{array}{l}\text { Highest ( } \sim 0.8 \mathrm{mg} \text { or more isoflavone per day) vs } \\
\text { lowest ( } \sim 0.15 \mathrm{mg} \text { or less isoflavone per day) }\end{array}$} \\
\hline$A \|^{a}$ & 11 & 1.04 & $(0.97-1.11)$ \\
\hline $\begin{array}{l}\text { Cohort/nested } \\
\text { case-control }^{\mathrm{b}}\end{array}$ & 4 & 1.08 & $(0.95-1.24)$ \\
\hline $\begin{array}{l}\text { Case-control } \\
\text { studies }^{c}\end{array}$ & 7 & 1.02 & $(0.95-1.11)$ \\
\hline
\end{tabular}

${ }^{a}$ Studies included in meta-analysis: Witte et al (1997); Horn-Ross et al (2001, 2002); Linseisen et al (2003); Peterson et al (2003); dos Santos Silva et al (2004); Grace et al (2004); Keinan-Boker et al (2004); Bosetti et al (2005); Touillaud et al (2006); Fink et al (2007). We estimated daily soy isoflavone intake in one study (Witte et al (1997) by assuming that one serving of tofu per week is $50 \mathrm{~g}$ and this is equivalent to $2.14 \mathrm{mg}$ isoflavone per day. ${ }^{b}$ Four cohort/nested case-control studies: Horn-Ross et al (2002): Grace et al (2004): Keinan-Boker et al (2004); Touillard et al (2006). 'Seven case-control studies: Witte et al (1997); Horn-Ross et al (200 I); Linseisan et al (2003); Peterson et al (2003); dos Santos Silva et al (2004); Bosetti et al (2005); Fink et al (2007). 


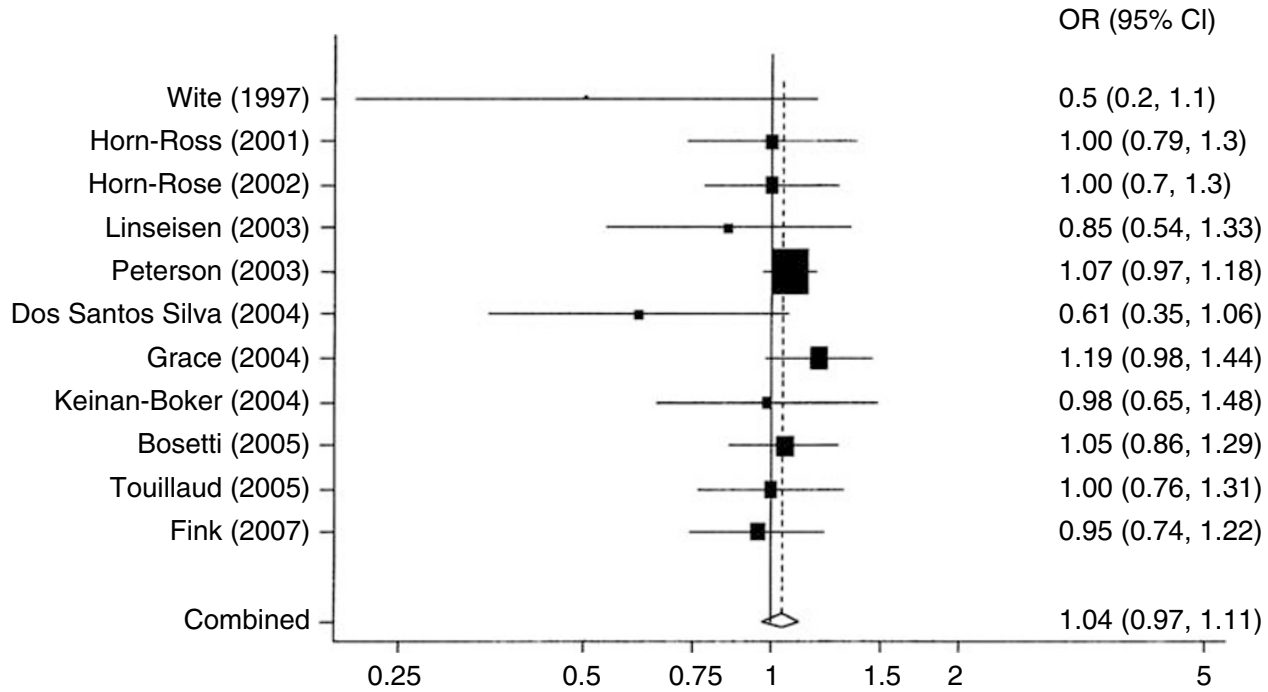

Figure 2 Highest ( $\sim 0.8 \mathrm{mg}$ or more isoflavones per day) vs lowest ( $\sim 0.15 \mathrm{mg}$ or less isoflavones per day) level of soy intake and breast cancer - II studies conducted in Western populations. Odds ratio (OR), 95\% Cl.

Francisco Bay Area, USA (Horn-Ross et al, 2001). Instead a considerable $(25-60 \%)$ proportion of soy isoflavones in these populations was from soy components added to typical Western foods including bakery and canned products.

Table 2 presents the meta-analysis results of these 11 studies in Western populations, showing no association between adult soy intake and breast cancer risk; the summary OR was $1.04(95 \%$ $\mathrm{CI}=0.97-1.11$ ) between the highest (median was $0.8 \mathrm{mg}$ or more per day) vs lowest (median was $0.15 \mathrm{mg}$ or less per day) soy isoflavone intake. Results of the individual studies are shown in Figure 2. There was no significant heterogeneity among the study results $(P=0.42)$. The summary ORs and corresponding 95\% CIs obtained from the four cohort/nested case-control studies and the seven case-control studies are overlapping.

In a few of these studies conducted in Western populations (Witte et al, 1997; Horn-Ross et al, 2001), risk patterns in relation to Asian soy foods (i.e., tofu and others) were presented. Results on these soy foods, at the relatively low levels consumed in the West, are compatible with those at corresponding consumption levels in Asian women.

To overcome the difficulties and imprecision associated with estimating low dietary soy intake from questionnaires, baseline, prediagnostic blood/urine isoflavone levels collected from participants of three cohorts were examined in relation to breast cancer risk (den Tonkelaar et al, 2001; Grace et al, 2004; Verheus et al, 2007); two of these studies also had information on dietary soy isoflavone intake (Grace et al, 2004; Keinan-Boker et al, 2004). The combined OR (summary OR $=1.02,95 \% \mathrm{CI}=0.84-1.23$ ) from these three nested case-control studies is consistent with the finding of no association based on dietary soy isoflavones and breast cancer risk in Western populations. There were no differences in results by menopausal status (Horn-Ross et al, 2001; dos Santos Silva et al, 2004; Keinan-Boker et al, 2004; Bosetti et al, 2005; Fink et al, 2007; Verheus et al, 2007). One study examined the soy-breast cancer association by body size and reported no differences in results (Bosetti et al, 2005).

Soy intake during adolescence and breast cancer risk was investigated in one large Canadian case-control study (Thanos et al, 2006). The authors reported a significant, inverse association with a score representing intake of foods considered rich in isoflavones. In this study population, few subjects $(<5 \%)$ reported intake of any soy foods (tofu, soybeans, soy milk and soy powder drinks) and the most likely sources of soy isoflavones were pancakes (mix), canned tuna and processed meats. The authors did not perform separate analyses by type of soy consumed (as food additives $v s$ as soy foods). Due to the possible differential effects of the two sources of dietary soy exposures on breast cancer risk, it is unclear if these findings truly reflect a beneficial effect of early life soy intake on breast cancer development.

\section{SOY AND BREAST CANCER SURVIVAL}

Few studies have investigated the effects of soy intake in women with breast cancer. Among Chinese women in Shanghai, usual soy food intake before breast cancer diagnosis was unrelated to disease-free breast cancer survival after a median follow-up of 5.2 years, but information on tamoxifen use was not included (Boyapati et al, 2005). To address the concern that soy may negate the effect of tamoxifen (Messina et al, 2006), we investigated and found no relationship between serum levels of tamoxifen or its metabolites and self-reported intake of soy or serum levels of isoflavones among a population-based sample of Asian-American women with breast cancer (Wu et al, 2007b). Further studies are needed to determine the effects of soy (before and after breast cancer diagnosis), in relation to tamoxifen use and breast cancer outcome.

\section{SOY AND MARKERS OF BREAST CANCER RISK}

It has been speculated that the protective effect of soy intake on breast cancer could be mediated through a hormonal mechanism, and that high soy intake may affect circulating levels of oestrogen and sex-hormone-binding globulins and mammographic densities in a favourable manner (Messina et al, 2006). There is suggestion in some cross-sectional studies that circulating oestrogen and androgen levels may be nonsignificantly decreased in association with high-soy food intake but these effects are typically small and the results are not consistent. Results from the nearly 20 shortterm intervention studies on soy (mainly given as supplements or other soy protein products) and circulating oestrogen and sexhormone-binding globulin are mixed and this may be related to differences in study design, small sample sizes, the amount and source of soy isoflavones that were used, duration of supplementation 
and other reasons (for a review, see Maskarinec et al, 2004; Wu et al, 2005).

Fewer studies have investigated the effect of soy intake on mammographic density. The strongest evidence that mammographic density is significantly reduced in association with highsoy food intake is based on a cross-sectional study we conducted among Chinese women in Singapore. In another cross-sectional study conducted in Hawaii, high soy intake was associated with lower mammographic density among Chinese and Japanese women in Hawaii but higher mammographic density in Caucasians and Hawaiians; none of the associations was statistically significant. Three intervention studies of 1-2 years duration, conducted in mostly premenopausal or perimenopausal women, failed to note any effects of soy, given as soy foods, red clover isoflavones or isoflavone supplements, on mammographic density (for a review, see Messina et al, 2006; Ursin et al, 2006).

Thus, the collective evidence based on circulating hormones and mammographic density does not show any strong or consistent oestrogenic or anti-oestrogenic effects of soy on the breast. Differences in intestinal microflora can influence the subsequent absorption and metabolism of soy intake. Approximately onethird of the population is capable of producing equol, a metabolite of daidzein. It has been suggested that differences in a woman's ability to produce equol may influence the extent to which her soy consumption can impact on her risk of breast cancer development (Setchell et al, 2002). At present, it is unclear whether failure to take account of the differences in soy metabolism between individuals has contributed to the inconsistencies between studies.

\section{CONCLUSIONS}

Overall data based on Asian women, mainly derived from casecontrol studies, show a dose-dependent, statistically significant association between soy food intake and breast cancer risk reduction. There was an approximately $16 \%$ risk reduction per $10 \mathrm{mg}$ of isoflavones intake per day. Age at exposure may be a co-determinant of risk; adolescent intake shows a stronger effect on risk than intake during adulthood. Soy intake was unrelated to breast cancer risk in studies conducted in Western populations in which the average intake of soy isoflavones was low $\left(<1 \mathrm{mg} \mathrm{day}^{-1}\right)$ and exposure is mainly in the form of soy components added as fillers/extenders to typical Western foods. There is little evidence of a modifying effect by menopausal status or body weight on the soy-breast cancer association. It is inconclusive whether habitual soy intake or shortterm soy supplementation influences circulating hormone levels or mammographic density. If the beneficial effect of Asian soy foods on breast cancer risk noted above is real, their mechanisms of action remain to be elucidated.

\section{ACKNOWLEDGEMENTS}

We are grateful to the contribution and support of all the study participants and the funding support from the California Breast Cancer Research Program (1RB-0287, 3PB-0102, 5PB-0018, 9PB0089) and the Susan G Komen Breast Cancer Foundation (BASIC99-00328, POP0201896).

\section{REFERENCES}

Bosetti C, Spertini L, Parpinel M, Gnagnarella P, Lagiou P, Negri E, Franceschi S, Montella M, Peterson J, Dwyer J, Giacosa A, La Vecchia C (2005) Flavonoids and breast cancer risk in Italy. Cancer Epidemiol Biomarkers Prev 14: 805-808

Boyapati SM, Shu XO, Ruan ZX, Dai Q, Cai Q, Gao YT, Zheng W (2005) Soyfood intake and breast cancer survival: a followup of the Shanghai Breast Cancer Study. Breast Cancer Res Treat 92: 11-17

Dai Q, Shu XO, Jin F, Potter JD, Kushi LH, Teas J, Gao YT, Zheng W (2001) Population-based case-control study of soyfood intake and breast cancer risk in Shanghai. Br J Cancer 85: 372-378

den Tonkelaar I, Keinan-Boker L, Veer PV, Arts CJ, Adlercreutz H, Thijssen JH, Peeters PH (2001) Urinary phytoestrogens and postmenopausal breast cancer risk. Cancer Epidemiol Biomarkers Prev 10: $223-228$

Do MH, Lee SS, Jung PJ, Lee MH (2007) Intake of fruits, vegetables, and soy foods in relation to breast cancer risk in Korean women: a case - control study. Nutr Cancer 57: 20-27

dos Santos Silva I, Mangtani P, McCormack V, Bhakta D, McMichael AJ, Sevak L (2004) Phyto-oestrogen intake and breast cancer risk in South Asian women in England: findings from a population-based casecontrol study. Cancer Causes Control 15: 805-818

Fink BN, Steck SE, Wolff MS, Britton JA, Kabat GC, Schroeder JC, Teitelbaum SL, Neugut AI, Gammon MD (2007) Dietary flavonoid intake and breast cancer risk among women on Long Island. Am J Epidemiol 165: $514-523$

Gilani GS, Anderson JJB (2002) Phytoestrogens and Health. Champaign, Il, USA: AOCS Press

Grace PB, Taylor JI, Low YL, Luben RN, Mulligan AA, Botting NP, Dowsett M, Welch AA, Khaw KT, Wareham NJ, Day NE, Bingham SA (2004) Phytoestrogen concentrations in serum and spot urine as biomarkers for dietary phytoestrogen intake and their relation to breast cancer risk in European prospective investigation of cancer and nutrition-norfolk. Cancer Epidemiol Biomarkers Prev 13: 698-708

Hargreaves DF, Potten CS, Harding C, Shaw LE, Morton MS, Roberts SA, Howell A, Bundred NJ (1999) Two-week dietary soy supplementation has an estrogenic effect on normal premenopausal breast. J Clin Endocrinol Metab 84: 4017-4024

Hirose K, Imaeda N, Tokudome Y, Goto C, Wakai K, Matsuo K, Ito H, Toyama T, Iwata H, Tokudome S, Tajima K (2005) Soybean products and

reduction of breast cancer risk: a case-control study in Japan. $\mathrm{Br} J$ Cancer 93: 15-22

Hirose K, Takezaki T, Hamajima N, Miura S, Tajima K (2003) Dietary factors protective against breast cancer in Japanese premenopausal and postmenopausal women. Int J Cancer 107: 276-282

Ho SY, Schooling M, Hui LL, McGhee SM, Mak KH, Lam TH (2006) Soy consumption and mortality in Hong Kong: proxy-reported case-control study of all older adult deaths in 1998. Prev Med 43: 20-26

Horn-Ross PL, Hoggatt KJ, West DW, Krone ML, Stewart SL, Anton-Culver H, Bernstein L, Deapen D, Peel D, Pinder R, Reynolds P, Ross RK, Wright W, Ziogas A (2002) Recent diet and breast cancer risk: the California Teachers Study (USA). Cancer Causes Control 13: 407-415

Horn-Ross PL, John EM, Lee M, Stewart SL, Koo J, Sakoda LC, Shiau AC, Goldstein J, Davis P, Perez-Stable EJ (2001) Phytoestrogen consumption and breast cancer risk in a multiethnic population: the Bay Area Breast Cancer Study. Am J Epidemiol 154: 434-441

Keinan-Boker L, van Der Schouw YT, Grobbee DE, Peeters PH (2004) Dietary phytoestrogens and breast cancer risk. Am J Clin Nutr 79: $282-288$

Key TJ, Sharp GB, Appleby PN, Beral V, Goodman MT, Soda M, Mabuchi K (1999) Soya foods and breast cancer risk: a prospective study in Hiroshima and Nagasaki, Japan. Br J Cancer 81: $1248-1256$

Lee HP, Gourley L, Duffy SW, Esteve J, Lee J, Day NE (1991) Dietary effects on breast-cancer risk in Singapore. Lancet 337: 1197-1200

Lee MM, Chang IY, Horng CF, Chang JS, Cheng SH, Huang A (2005) Breast cancer and dietary factors in Taiwanese women. Cancer Causes Control 16: $929-937$

Linseisen J, Piller R, Hermann S, Chang-Claude J (2004) Dietary phytoestrogen intake and premenopausal breast cancer risk in a German case-control study. Int J Cancer 110: 284-290

Maskarinec G, Franke AA, Williams AE, Hebshi S, Oshiro C, Murphy SP, Stanczyk FZ (2004) Effects of a 2-year randomized soy intervention on sex hormone levels in premenopausal women. Cancer Epidemiol Biomarkers Prev 13: 1736 - 1744

Messina M, McCaskill-Stevens W, Lampe JW (2006) Addressing the soy and breast cancer relationship: review, commentary, and workshop proceedings. J Natl Cancer Inst 98: 1275-1284

Nishio K, Niwa $Y$, Toyoshima $H$, Tamakoshi $K$, Kondo T, Yatsuya H, Yamamoto A, Suzuki S, Tokudome S, Lin Y, Wakai K, Hamajima N, 
Tamakoshi A (2007) Consumption of soy foods and the risk of breast cancer: findings from the Japan Collaborative Cohort (JACC) Study. Cancer Causes Control 18: 801-808

Peterson J, Lagiou P, Samoli E, Lagiou A, Katsouyanni K, La Vecchia C, Dwyer J, Trichopoulos D (2003) Flavonoid intake and breast cancer risk: a case - control study in Greece. Br J Cancer 89: 1255-1259

Setchell KD, Brown NM, Lydeking-Olsen E (2002) The clinical importance of the metabolite equol-a clue to the effectiveness of soy and its isoflavones. J Nutr 132: $3577-3584$

Shannon J, Ray R, Wu C, Nelson Z, Gao DL, Li W, Hu W, Lampe J, Horner N, Satia J, Patterson R, Fitzgibbons D, Porter P, Thomas D (2005) Food and botanical groupings and risk of breast cancer: a case - control study in Shanghai, China. Cancer Epidemiol Biomarkers Prev 14: 81-90

Shu XO, Jin F, Dai Q, Wen W, Potter JD, Kushi LH, Ruan Z, Gao YT, Zheng W (2001) Soyfood intake during adolescence and subsequent risk of breast cancer among Chinese women. Cancer Epidemiol Biomarkers Prev 10: 483-488

Thanos J, Cotterchio M, Boucher BA, Kreiger N, Thompson LU (2006) Adolescent dietary phytoestrogen intake and breast cancer risk (Canada). Cancer Causes Control 17: 1253-1261

Touillaud MS, Thiebaut AC, Niravong M, Boutron-Ruault MC, ClavelChapelon F (2006) No association between dietary phytoestrogens and risk of premenopausal breast cancer in a French cohort study. Cancer Epidemiol Biomarkers Prev 15: 2574-2576

Trock BJ, Hilakivi-Clarke L, Clarke R (2006) Meta-analysis of soy intake and breast cancer risk. J Natl Cancer Inst 98: 459-471

Ursin G, Sun CL, Koh WP, Khoo KS, Gao F, Wu AH, Yu MC (2006) Associations between soy, diet, reproductive factors, and mammographic density in Singapore Chinese women. Nutr Cancer 56: 128-135
Verheus M, van Gils CH, Keinan-Boker L, Grace PB, Bingham SA, Peeters PH (2007) Plasma phytoestrogens and subsequent breast cancer risk. J Clin Oncol 25: 648-655

Witte JS, Ursin G, Siemiatycki J, Thompson WD, Paganini-Hill A, Haile RW (1997) Diet and premenopausal bilateral breast cancer: a case-control study. Breast Cancer Res Treat 42: 243-251

Wu AH, Yu MC, Tseng CC, Pike MC (2007a) Body size, hormone therapy and risk of breast cancer in Asian-American women. Int J Cancer 120: $844-852$

Wu AH, Pike MC, Williams LD, Spicer D, Tseng CC, Churchwell MI, Doerge DR (2007b) Tamoxifen, soy, and lifestyle factors in Asian American women with breast cancer. J Clin Oncol 25: 3024-3030

Wu AH, Stanczyk FZ, Martinez C, Tseng CC, Hendrich S, Murphy P, Chaikittlsilpa S, Stram DO, Pike MC (2005) A controlled 2-mo dietary fat reduction and soy food supplementation study in postmenopausal women. Am J Clin Nutr 81: 1133-1141

Wu AH, Wan P, Hankin J, Tseng CC, Yu MC, Pike MC (2002) Adolescent and adult soy intake and risk of breast cancer in Asian-Americans. Carcinogenesis 23: 1491-1496

Wu AH, Ziegler RG, Horn-Ross PL, Nomura AM, West DW, Kolonel LN, Rosenthal JF, Hoover RN, Pike MC (1996) Tofu and risk of breast cancer in Asian-Americans. Cancer Epidemiol Biomarkers Prev 5: 901-906

Yamamoto S, Sobue T, Kobayashi M, Sasaki S, Tsugane S (2003) Soy, isoflavones, and breast cancer risk in Japan. J Natl Cancer Inst 95: 906-913

Yuan JM, Wang QS, Ross RK, Henderson BE, Yu MC (1995) Diet and breast cancer in Shanghai and Tianjin, China. Br J Cancer 71: 1353-1358 